\title{
Helicobacter Increase Instability Genome in Mucous Cells of Antrum of Stomach Mucous in People, Who Lives in Radiation Contaminated Areas
}

\author{
Sergey Lopatin1, Viacheslav Kravtsovi,2*, Sergey Dudarenko', Vera Ellinidi1 \\ ${ }^{1}$ The Nikiforov Russian Center of Emergency and Radiation Medicine EMERCOM, Saint-Petersburg, Russia \\ ${ }^{2}$ Pushkin Leningrad State University, Saint-Petersburg, Russia \\ Email: ${ }^{*}$ kvyspb@rambler.ru
}

Received 28 January 2015; accepted 20 March 2015; published 25 March 2015

Copyright (C) 2015 by authors and Scientific Research Publishing Inc.

This work is licensed under the Creative Commons Attribution International License (CC BY).

http://creativecommons.org/licenses/by/4.0/

(c) (i) Open Access

\begin{abstract}
The research of degree of incidence of genomic changes (of micronuclei) in mucous cells of gastric superficial-foveolar epithelium in contaminated and not contaminated mucous of stomach was made. Histopathological research of micronuclei and helicobacter was made in gastric biopsy specimen of patients with diagnosis-chronical gastritis (ICD-10K29.3) in group of patients who lived in radiation contaminated areas and in groups of people, who had no factors of radiation influence in anamnesis. People, who lived in the radiation contaminated areas, whose mucous was infected by Helicobacter pylori, had the highest frequency of mucous cells with micronuclei. In the group of patients from radiation contaminated areas with HP-associated gastritis frequency of appearance of mucous cells with micronucleus in the mucous of stomach have five time more, than patients, whose mucous of stomach was not infected $(p<0.001)$. Therefore, we can suggest, that Helicobacter pylori can success in mutagenic effect of radiation factor.
\end{abstract}

\section{Keywords}

Helicobacter pylori, Immunohistochemistry, Micronuclei, Mucous Cells of the Stomach, Chernobyl Accident

\section{Introduction}

As the present time is proved, that epithelial cells of the stomach mucous, that infected by Helicobacter pylori,

*Corresponding author.

How to cite this paper: Lopatin, S., Kravtsov, V., Dudarenko, S. and Ellinidi, V. (2015) Helicobacter Increase Instability Genome in Mucous Cells of Antrum of Stomach Mucous in People, Who Lives in Radiation Contaminated Areas. Health, 7, 413-418. http://dx.doi.org/10.4236/health.2015.73047 
are more sensitive to other damaged agents, than not infected cells [1] [2], and Helicobacter pylori is acknowledged as carcinogen (WHO). Risks of malignant changes of somatic cells are increased with radiation effect from outside environment. In reference with the above, we can expect the increase of frequency of genome disorder in stomach mucous cell in population of people who have both risk factors, named above: inhabitancy and feeding in the radiation contaminated areas with intragastric HP infection.

At the present time, micronucleus test is used for quantitative ratings of genome disorder in epithelial cells of gastrointestinal tract (GIT) [3]. Micronuclei appears during cell division from chromosome material, which lost contact with cleavage spindle. They include chromatin of acentric fragment or full chromosome (chromatid). Degree of incidence of cells with micronuclei can indicate the incidence of appearance of cells with changed karyotype. Micronucleus test allow us to rate cytological instability in cell population in vivo, and also in population of epithelial cells of GIT [4]-[6]. Usually, micronucleus test is made in cell populations in cell smears, but it can be also done in the histological section [1] [5]-[10]. So, for example, Japanese scientists in 2013 (Ohyama W and others, 2013) made research about carcinogen instability of stomach and colon mucous cells (based on micronucleus test) after single dose of carcinogen per os (N-nitroso-N-methylurea, N-methyl-N-nitro-M-nitrosoguanidine) [3]. In this research it was shown, that after a single dose of carcinogen (N-nitroso-N-methylurea, N-methyl-Nnitro-M-nitrosoguanidine) frequency of micronuclei in rats mucous of stomach was evidentially increased. In the conclusion of this research was made the assumption, that micronucleus test can be used in histological section of gastric biopsy specimen for value of cytological instability of mucous cells of GIT.

We had the archive of paraffin blocks of gastric biopsy specimen, which was received after fibrogastroduodenoscopy of 2686 patients, who were investigated and treated in Choiniki central district hospital in 1988-1993 (Choiniki, Gomel region, Republic of Belarus). As a reminder, in 1986, $30 \mathrm{~km}$ from this area was Chernobyl accident. When we received these histological sections from these blocks, we made retrospective research of degree of incidence of micronuclei in mucous cells of gastric superficial-foveolar epithelium at the same time as micronucleus test-immunohistochemical test of Helicobacter pylori.

In this research, we show the results of investigation, using micronucleus test, of genome instability in cell population of mucous cells of stomach mucous of people who live in radiation contaminated areas with HP-associated diseases of GIT and people with GIT diseases, but without HP infected mucous of stomach mucous.

The protocol for the research project was approved by the appropriate ethics committee at a meeting The Nikiforov Russian Center of Emergency and Radiation Medicine EMERCOM as appropriate ethical standards.

\section{Materials and Method}

There were made 586 fibrogastroduodenoscopy and evaluated results of 2682 patients, who were investigated and treated in Choiniki central district hospital in 1988-1993 (Choiniki, Gomel region, Republic of Belarus). Contamination density in this area, after Chernobyl accident was, as for ${ }^{137} \mathrm{Cs}(7.67 \pm 0.12) \mathrm{Ci} / \mathrm{km}^{2}$, as for ${ }^{90} \mathrm{Sr}$ $(1.15 \pm 0.01) \mathrm{Ci} / \mathrm{km}^{2}$, gamma-ray background of the area $(45.9 \pm 0.7) \mathrm{mcR} / \mathrm{h}$.

The research was made in two groups of patients, who have histological chronical gastritis with low grade inflammation. After fibrogastroduodenoscopy 118 patients, were found with chronical gastritis with low grade inflammation in Belarus and in Saint Petersburg. Group 1 included 50 people (including 22 men and 28 women) who are permanent residents in Choiniki's region (since Chernobyl accident) and who were investigated and treated in Choiniki central district hospital in 1988-1993 (Choiniki, Homel region, Republic of Belarus). The average age of the cohort of men surveyed in 1988-1993 was 30.3 years, and women-32.3 years. Group 2 included 68 patients (including 36 women and 32 men), who lives in Saint-Petersburg and were investigated and treated in The Federal State Budgetary Institute "The Nikiforov Russian Center of Emergency and Radiation Medicine” in 2011, and who had no radiation effects in anamnesis, excluding only medical diagnostic procedure. The average age of men in this group was 54.2, and women-54.3 years. These two groups were also shared, according to Helicobacter pylori content of stomach mucous. Subset of Helicobacter pylori-negative patients from radiation contaminated areas (“1A”) included 28 patients, Helicobacter pylori-positive (“1B”)—-22 patients. The group from Saint Petersburg was also divided in to 2 subsets: Helicobacter pylori-negative patients (38 patients), Helicobacter pylori-positive (30 patients) (Table 1).

The method of instrumental diagnostic includes fibrogastroduodenoscopy with biopsy of stomach mucous. Target biopsy was received from antrum. Biopsy material was fixed in 10\% formalin and paraffin-embedded and put on the mounting slide. Histological sections, that were fixed in spirit: acetone in the ratio 1:1 during 10 
Table 1. Groups of patients with chronical gastritis (According to fibrogastroduodenoscopy).

\begin{tabular}{ccccc}
\hline & \multicolumn{3}{c}{ Number of individuals in subset, who lives in } \\
\cline { 2 - 4 } Chronical gastritis & Radiation contaminated areas & \multicolumn{2}{c}{ Saint Petersburg } \\
\cline { 2 - 4 } & $1 \mathrm{~A}$ & $1 \mathrm{~B}$ & $2 \mathrm{~A}$ & $2 \mathrm{~B}$ \\
\hline Not infected mucous of stomach by Helicobacter pylori & 28 & 0 & 38 & 0 \\
Infected stomach mucous by Helicobacter pylori & 0 & 22 & 0 & 30 \\
\hline
\end{tabular}

min, was dried and inactivated endogenic peroxidase in 1\% sodium azide (Merck) for 15 min. than it was washed twice in double-distilled water and left for 5 min in Tris-buffered saline (pH 7.6).

Before application of preimmune porcine serum, the area for immunohistochemical test was localized by hydrophobic pencil (DakoCytomation). After incubation with preimmunic serum (30 min in room air) was laid on polyclonal rabbits antibody (NCL-HPp, Novocastra), which are directed against antigen of the cell border of Helicobacter pylori, and then the samples were incubated during 3 hours with temperature +37C. After tagging by the first antibodies, rhe samples were put into buffers for 5 min twice and then was applicated biotinylated antibodies (DakoCytomation), which are directed against rabbit's antibodies. With the second antibodies, samples were incubated during $15 \mathrm{~min}$ in room air. The next step of immunohistochemical procedure, after washing twice in buffers, was application of system of visualization, which contains avidin and biotinylated peroxidase of horse-radish (DakoCytomation) for $10 \mathrm{~min}$ in room air. As a substrate for immunohistochemical reaction was used 3,3'-diaminobenzidine (Novocastra). Than samples were stained with haematoxylin.

Analysis of samples was made by immersion lens on microscope LeicaDM $4000 \mathrm{~B}$. To find Helicobacter pylori 300 microscope field of view were watched through. The positive result-infection by Helicobacter pylori was registrate if in 300 microscope field of view were found not less than 5 bacterial cells with species-specific antigen of Helicobacter pylori. Helicobacter pylori had colors from dark-brown to light-brown.

For research of micronucleus was chose antral mucous, because in this part there are no parietal cells. In cytoplasm of these cells there are spheres, which can imitate micronuclei, because of its shape and size and distort (increase) the result of micronucleus test in histological section. At the present time, it is proved that there is no significant difference in quantity of mucous cells with micronuclei in the body of stomach and in the antrum [5]. Micronucleus test, as usual, is made in cell population in cell smears, but it can be also done in histological section [1].

Calculation of micronuclei in mucous cells of stomach mucous was made in high power field (1000). In each observation from 2400 to 15,000 mucous cells of stomach mucous were watched. During calculation only cylindrical epithelial cells of gastric pits were counted. Cells in the gland structure were not observed. Mucous cells were related to cells with micronucleus only with: a) overlaying cells upon each other was not allowed; b) main nucleus and micronucleus were placed in cytoplasm in the same optical field; c) the character of coloration of chromatin of micronucleuses was the same or a little bit paler than main nucleus; d) micronuclei had round or oval shape; e) borders of micronucleuses was clear and apart from the nucleus. Absences of this signs were the criterion of exclusion calculated micronuclei.

For statistical analysis during the comparing of results of the groups was used t-test and nonparametric MannWhitney U-test.

\section{Result and Discussion}

In histological section of gastric biopsy specimen from stomach mucous which are stained with haematoxylin and eosin, micronucleoses in mucous cells of gastric superficial-foveolar epithelium are mostly complained by color, chromatic gritness and color density with cell's nucleus, in which it was found (Figure 1). Sizes of micronuclei were not bigger than $1 / 4$ of nucleus area of the same cell and absolute sizes (diameter) of micronuclei in the mucous cells are from 2 to $4 \mathrm{mkm}$. Shape of the micronuclei of the mucous cells was always round or oval. Micronuclei in the mucous cells was near with the nucleus, mostly in basalic position, or apically. It's important to note, that in the section, in which was micronuclei, mucous cells with micronuclei was near, within the bounds of one pit of surface epithelium. Morphologically, people from radiation contaminated areas, have low grade signs of swelling of the mucous of antrum, eosinophilic, plasmocytic and lymphocytic infiltration of the 
mucous (Figure 1).

Patient from the 1st group have variation of range of frequency of mucous cells with micrinucleouses was from 0.00 to $1.04 \%$. Middle degree of incidence of mucous cells of stomach mucous with micronuclei was $(0.10 \pm 0.02) \%$. In the 2 nd group variation of range was from 0.00 to $0.40 \%$. Middle degree of incidence of mucous cells of stomach mucous with micronuclei was $(0.02 \pm 0.008) \%$ (Figure 2). U-test revealed differences between degrees of incidence of mucous cells of stomach mucous with micronucleuses between groups $(\mathrm{p}<0.01)$.

Therefore, this data shows significant difference of "frequency of mucous cells of stomach mucous with micronuclei" between people from radiation contaminated areas and people, who had not any radiative effect in anamnesis, excluding diagnostic procedures.

Let's consider the same parameters, but with contamination with Helicobacter pylori. The "1A" subset HPnegative patients, who live in radiation contaminated areas, frequency of mucous cells with micronuclei was $(0.06 \pm 0.017) \%$. This parameter is significantly different $(p<0.01)$ from subset " $1 B$ " HP-positive patients, who live in radiation contaminated areas, where frequency of mucous cells with micronuclei was $(0.16 \pm 0.03) \%$ and " $2 \mathrm{~A}$ " subset HP-negative patients who live in Saint Petersburg - with the frequency of mucous cells with micronucleuses is $(0.01 \pm 0.005) \%$. In subset "2B" HP-positive patients, who live in Saint Petersburg-the frequency of mucous cells with micronuclei $(0.03 \pm 0.015) \%$, significant difference is not found $(p>0.05)$ during comparing with " $1 \mathrm{~A}$ " and " $2 \mathrm{~A}$ " subsets (Figure 3).

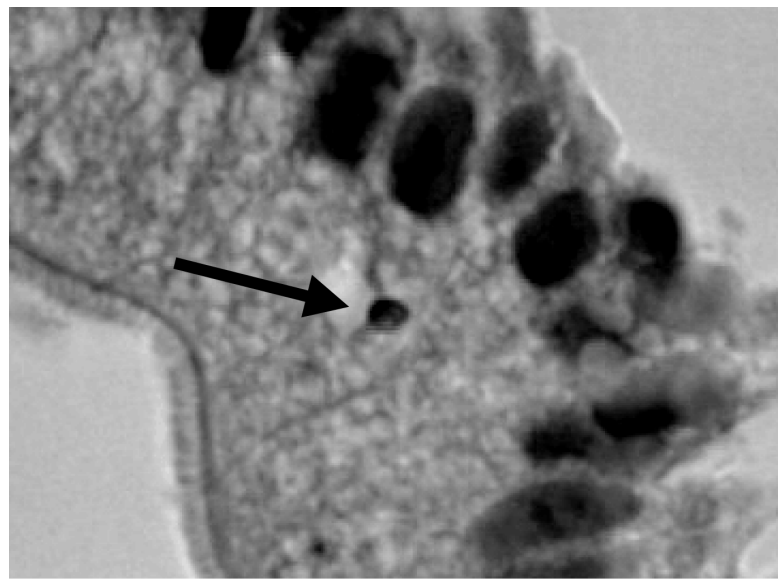

Figure 1. Round-shape micronucleus in the cylindrical epithelial cells of the stomach mucous. Colored by haematoxylin and eosin. Zooming 1000 (objective 100; ocular 10×).

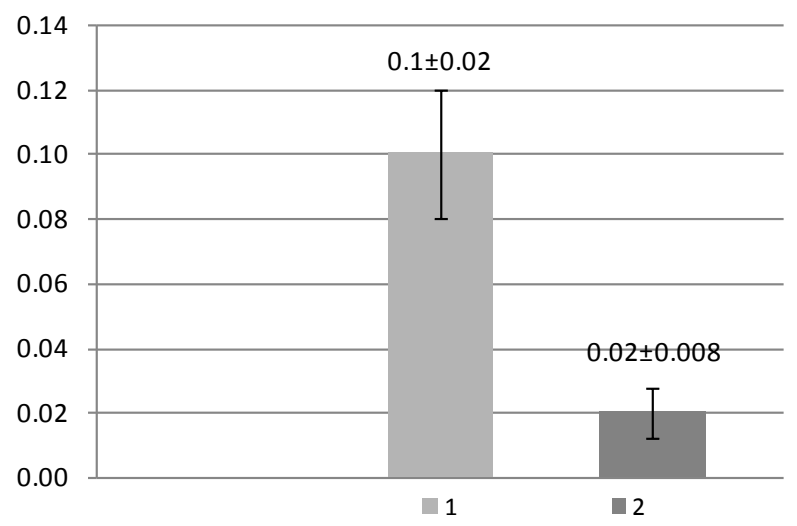

Figure 2. Frequency of micronucleated mucocytes (Y-coordinate in permille) in a mucous membrane of stomach in Group 1 of people from radiation contaminated areas (1) and in control Group 2 from Saint-Petersburg (2), excluding contaminated by Helicobacter pylori. 


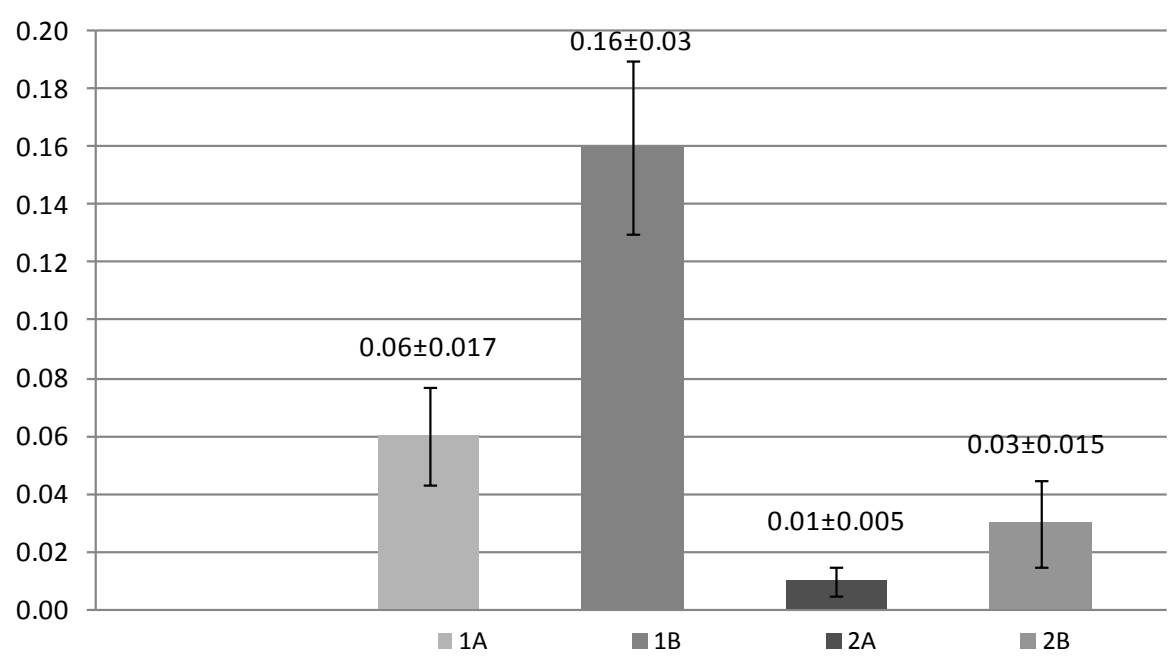

Figure 3. Frequency of micronucleated mucocytes (Y-coordinate-in permille) in a mucous membrane of stomach in Grpoup 1 of people from radiation contaminated areas (1) and in control Group 2 from Saint-Petersburg (2), including contamination by Helicobacter pylori (B). 1A and 2A-helicobacter-negative persons. $1 \mathrm{~B}$ and $2 \mathrm{~B}$-helicobacter-positive persons.

Evidently, that contamination of the stomach mucous with Helicobacter pylori is accompanied by the increased frequency of mucous cells with cytogenetic disorders (micronuclei) in the antrum of stomach mucous. The highest level of mucous cells was found in subset " $1 \mathrm{~B}$ " (people from radiation contaminated areas with HP-positive diseases of GIT), where this parameter was 5 times higher than the same parameter in HP-positive patients from Saint-Petersburg.

The results of the research can allow us to resume, that increased cytogenetic instability of mucous cells of this group is caused by increased Helicobacter pylori contamination and constant influence of radiation agent.

It is known, that inflammatory process of any etiology is accompanied by immune reaction. In the focus of inflammation we can see increased free radical processes, which leads to increased concentration of free radicals and products of free radical oxidation-superoxide radical $\mathrm{O}_{2}^{-}$, hydroxyl radical $\mathrm{OH}^{-}$, peroxynitrites $\mathrm{ONOO}^{-}$. Chronical inflammatory processes also accompanied by changes, which lead to markable decrease of oxygen diffusion to the epithelial cells; increased mutagenic process in epithelial cells is caused by, probably, decreased expression of reparation gene of DNA during oxygen deficiency [2]. Mutagenic effect from free radicals of oxygen can be corrected with antioxidant system. But, prolonged colonization by bacterial cells Helicobacter pylori decreases concentration of different antioxidant compound in stomach. Also, chronic infection by cytolethal distending toxin-producing helicobacter may promote malignant transformation, and point to the impairment of cellular control mechanisms associated with the detection and repair of DNA damage as critical events in the process [11].

Factors, that relate to Chernobyl accident are: social stress; psychological stress, because of absence of significant information about effect of radiation on health; changed food ration and life style of citizens; possibility of incorporation of radionuclide with food; influence of low dosage of external and internal radiation (according to officially published data-cancerogenic risk of oncological pathology of digestive system of people from radiation contaminated areas after 10 - 15 years after Chernobyl accident was miniscule and did not exceed the overall average in Russia.)

Therefore, we can suggest, that Helicobacter pylori potentiate mutagenic effects of radiation factors. As a result, according to modern concept of cancerogenese, where mutagenic changes cells is the base, patients with high contamination with Helicobacter pylori and who lives in radiation contaminated areas can be include to the group of high oncological risk. Also, it is reasonable for people with oncology (thyroid cancer) to do eradication of Helicobacter pylori before Radioiodine Therapy, when patients take radioiodine per os.

\section{Conclusion}

The significant difference was revealed between people from radiation contaminated areas and people, who had 
no radiation influence in terms of "frequency of mucous cells in stomach mucous with micronucleuses”. Maximum frequency of mucous cells with micrinucleuses was found in people from radiation contaminated areas, whose stomach mucous was infected by Helicobacter pylori. In the group of patients from radiation contaminated areas with Helicobacter pylori-associated gastritis frequency of detecting mucous cells with micronucleuses in stomach mucous was 5 times higher, than in the group of patients, whose mucous was not infected by Helicobacter pylori $(\mathrm{p}<0.001)$. Therefore, we can suggest that Helicobacter pylori potentiate mutagenic effects of radiation factors. Of course, we recognize that the micronucleus test is the routine method for detecting genomic instability. However, in the unique gastrobiopsies preserved after Chernobyl, micronucleus test until the only possible method, which showed that Helicobacter enhances genomic instability in gastric mucocytes in people, who lived in radiation contaminated areas.

\section{References}

[1] Köhler, A. and Ellesat, K. (2008) Nuclear Changes in Blood, Early Liver Anomalies and Hepatocellular Cancers in Flounder (Platichthysflesus L.) as Prognostic Indicator for a Higher Cancer Risk? Marine Environmental Research, 66, 50-149. http://dx.doi.org/10.1016/j.marenvres.2008.02.071

[2] Zhang, Z. and Farthing, M. (2000) Helicobacter pylori in Gastric Malignancy: Role of Oxidants, Antioxidants and Other Co-Factors/Helicobacter pylori. In: Hunt, R. and Tytgat, G., Eds., Basic Mechanisms to Clinical Cure, Kluwer Academic Publishers, Dordrecht, 689 p.

[3] Ohyama, W., Okada, E., Fujiishi, Y., Narumi, K. and Yasutake, N. (2013) In Vivo Rat Glandular Stomach and Colon Micronucleus Tests: Kinetics of Micronucleated Cells, Apoptosis, and Cell Proliferation in the Target Tissues after a Single Oral Administration of Stomach- or Colon-Carcinogens. Mutation Research-Genetic Toxicology and Environmental Mutagenesis, 755, 141-147. http://dx.doi.org/10.1016/j.mrgentox.2013.06.016

[4] Kravtsov, V.Y. and Kitaeva, L.V. (2011) Helicobacter pylori Infection and Mucocytes with Micronuclei in the Gastric Mucosa from the Liquidator. Medical-Biological and Social-Psychological Issues of Safety in Emergency Situations, 2, 84-88.

[5] Kitaeva, L.V., Mikhailova, I.A., Semov, D.M., Proshin, S.N. and Kravtsov, V.Y. (2008) Micronuclei in Mucose Cells and Colonization of Human Stomach Epithelium with Coccoid Forms of Helicobacter pylori. Tsitologiia, 2, 160-164.

[6] Speit, G., Schütz, P., Weber, I., Ma-Hock, L., Kaufmann, W., Gelbke, H.P. and Durrer, S. (2011) Analysis of Micronuclei, Histopathological Changes and Cell Proliferation in Nasal Epithelium Cells of Rats after Exposure to Formaldehyde by Inhalation. Mutation Research-Genetic Toxicology and Environmental Mutagenesis, 721, 35-127. http://dx.doi.org/10.1016/j.mrgentox.2011.01.008

[7] Lisochkin, B.G., Kravtsov, V.Y. and Rybachenko, V.V. (2004) Retrospective Diagnosis of Radiation Inhalation Lesions of the Bronchial Mucosa in Clean-Up Personnel after the Nuclear Accident at the Chernobyl Nuclear Reactor Using the Micronucleus Test. Archives of Pathology, 2, 17-19.

[8] Caruso, R.A., Fedele, F., Crisafulli, C., Paparo, D., Parisi, A., Lucianò, R. and Cavallari, V. (2011) Abnormal Nuclear Structures (Micronuclei, Nuclear Blebs, Strings, and Pockets) in a Case of Anaplastic Giant Cell Carcinoma of the Thyroid: An Immunohistochemical and Ultrastructural Study. Ultrastructural Pathology, 35, 8-14. http://dx.doi.org/10.3109/01913123.2010.517899

[9] Chitcholtan, K., Hampton, M.B. and Keenan, J.I. (2008) Outer Membrane Vesicles Enhance the Carcinogenic Potential of Helicobacter pylori. Carcinogenesis, 29, 5-12. http://dx.doi.org/10.1093/carcin/bgn218

[10] Arabski, M., Klupinska, G., Chojnacki, J., Kazmierczak, P., Wisniewska-Jarosinska, M., Drzewoski, J. and Blasiak, J. (2005) DNA Damage and Repair in Helicobacter pylori-Infected Gastric Mucosa Cells. Mutation Research-Genetic Toxicology and Environmental Mutagenesis, 570, 129-135. http://dx.doi.org/10.1016/j.mrfmmm.2004.10.006

[11] Guidi, R., Guerra, L., Levi, L., Stenerlöw, B., Fox, J.G., Josenhans, C., Masucci, M.G. and Frisan, T. (2013) Chronic Exposure to the Cytolethal Distending Toxins of Gram-Negative Bacteria Promotes Genomic Instability and Altered DNA Damage Response. Cellular Microbiology, 15, 98-113. http://dx.doi.org/10.1111/cmi.12034 